\title{
Corrigendum: Climate change in sub-Saharan Africa: Nature restoration as an ethical issue
}

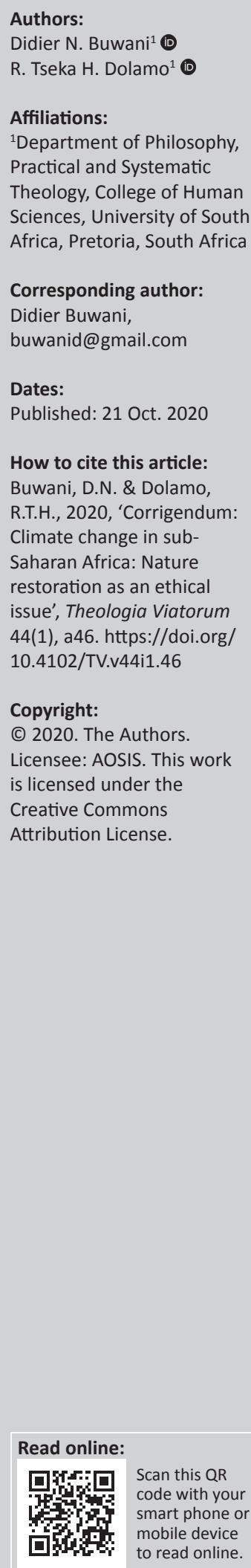

\section{Copyright:}

(C) 2020. The Authors. Licensee: AOSIS. This work

is licensed under the

Creative Commons

Attribution License.

In the version of the article initially published, Buwani, D.N. \& Dolamo, R.T.H., 2019, 'Climate change in sub-Saharan Africa: Nature restoration as an ethical issue', Theologia Viatorum 43(1), a4. https:/ / doi.org/10.4102/TV.v43i1.4, on page 4, the acronym 'REDD' was incorrectly defined. The correct definition for the acronym 'REDD' should be 'reducing emission from deforestation and forest degradation' instead of 'deforestation and forest degradation'. The correct definition of the term is updated in the sentence as follows:

Therefore, mechanisms to conserve the forest, such as reducing emission from deforestation and forest degradation (REDD), could assist in the mitigation of climate change, reduce vulnerability and enable people to adapt (Peach Brown et al. 2014:759).

This correction does not alter the study's findings of significance or overall interpretation of the study's results. The authors apologise for any inconvenience caused. 